the former then it could be speculated that the perceived lack of hope for his future in his carers may have had an effect on the distressed patient. Morgan (1981) has stressed the suicidal patient's ambivalence about life and death and the importance of staff in kindling hope rather than giving permission to die. If the latter is true, it is clear that for at least some nurses the myth has been established that there are some patients who 'cannot be helped'. Such myths can be perpetuated by reviews that conclude that everything possible had been done. The death of a patient by his own hand is a distressing event for all the professionals involved. Clearly it is not helpful or fair to attempt to apportion blame, but at the same time there may be useful lessons to be learnt from such a tragic event. We are still a long way from understanding the complex behaviour of suicide. Many factors are involved, mental illness being just one of them. It may be that the way such patients are handled by staff is important. It is recognised that the interaction between staff and patients can influence a patient's perspective on a problem (Rosenthal, 1976).

There is some evidence that suicide among psychiatric patients is increasing (Hesso, 1977). This may therefore be a good time to reassess how such events are handled as it is clearly important to give sensitive support to staff, but at the same time not to lose the chance of learning from the tragedy.

\section{References}

Hesso, R. (1977) Suicide in Norwegian, Finnish and Swedish psychiatric hospitals. Archiv für psychiatrie und nervenkrankheiten, 224, 119-127.

LANGLEY, G. E. \& BAYATTI, N. N. (1984) Suicides in Exe Vale Hospital, 1972-1981. British Journal of Psychiatry, 145, 463-467.

MORGAN, H. G. (1981) Management of suicidal behaviour. British Journal of Psychiatry, 138, 257-260.

ROSENTHAL, R. (1976) Experimenter Effects on Behavioural Research. Howard University. New York: Irvington Publishers.

Salmons, P. H. (1984) Suicide in high buildings. British Journal of Psychiatry, 145, 469-472.

TenRoch, E., PUgh, T. F. \& MaCmahon, B. (1984) Suicide rates amongst current and former mental institution patients. Journal of Nervous and Mental Diseases, 138, 124-130.

\section{Appendix}

(1) Do you think that this patient was a chronic patient?

(2) Do you think that this patient would have required psychiatric treatment again in the future?

(3) Do you think that this patient's long-term prognosis was good?

(4) Could any more have been done for this patient?

(5) Would it have made a difference to the long-term outcome?

\title{
Privatisation of psychiatric care in the USA
}

\author{
Mohan P. Das, Diplomate of the American Board of Psychiatry and Neurology and \\ Associate Medical Director, Mental Health/Mental Retardation Center of East Texas, \\ Texas 75712, USA
}

Privatisation of psychiatric care is an increasing phenomenon in the USA. This is a relatively new trend and has followed on the heels of other trends like the deinstitutionalisation of the 1960 s and 70 s.
Until recently the majority of in-patient population was in public hospitals, with some in psychiatric units of general hospitals. In the 1980 s, the private hospital corporations seem to have discovered that there is 
money to be made in the business of psychiatric care and started building and marketing psychiatric hospitals on a wide scale.

\section{History}

A number of factors have contributed to the rapid development of private psychiatric hospitals in the United States. One of the key factors was the easing by state authorities of some regulations which were blocking the free-flow of market forces. Until recently, prior to building a hospital, the state authorities had to agree that there was a need for such a facility in the area. As part of the deregulation of all industries started by the Carter administration, various state authorities discontinued the 'Certificate of Need' provision for hospitals. This encouraged the multi-hospital corporations to use their investors' shareholders' money to build new psychiatric facilities. This had a dramatic impact. For instance, it is reported that these corporations started building eight psychiatric hospitals in the Salt Lake City area alone within a period of nine months after Utah state discontinued the Certificate of Need regulations.

Initially most of the hospitals were built in major metropolitan areas, although now there is a tendency towards building new facilities in small centres with a population of 100,000 or more. Also, the hospital corporations which own general hospital chains have seen their profits decline because of the prospective payment regulations of federal health care programmes like Medicare (for over 65 year-olds) which set a dollar cap for payment based on diagnosis. As these regulations affect psychiatric hospitalisations to a smaller extent than medical/surgical care, many of these corporations have converted general medical and surgical beds to psychiatric beds to increase their profits. Another trend which seems to have increased the drive for privatisation is, ironically, the pressures to contain cost of medical care. Public agencies and community mental health centres were encouraged to purchase specific services from private providers. For instance, community mental health centres which found it expensive to run 'crisis resolution units' bought in-patient services from private hospitals. Better insurance coverage for psychiatric problems has also contributed to the growth of privatisation of psychiatric care.

\section{Current status}

All the trends mentioned above led to an expansion in the number of privately held psychiatric beds. It is estimated that private in-patient psychiatric beds have increased from $7 \%$ to $35 \%$ between 1970 and 1987. The ownership of psychiatric hospitals by proprietary companies also increased by $31 \%$ between
1983 and 1986. It is reported that the private psychiatric hospital corporations earned more than 2.5 billion dollars in 1985. Several private hospital corporations continue to build newer facilities after conducting some market studies, and major corporations plan to increase the construction of new psychiatric hospitals by $10 \%$ to $20 \%$ per year. The US health care system is based on a competitive model and the hospitals and providers of health care, and other agencies, have to compete for ever-shrinking health care dollars. In most major metropolitan areas, the competition between existing facilities is very stiff. The providers have responded by developing and aggressively marketing specialised services like units for eating disorders, neuropsychiatric units, and geriatric psychiatry services. At present the growth areas seem to be substance abuse programmes, and services for children and adolescents, with special tracks for adolescent substance abusers. National Institute of Mental Health data indicate that between $1970-80$, there has been a doubling of in-patient psychiatric beds for patients under 18, with a quadrupling of admissions of adolescents to private psychiatric hospitals between 1980-84.

\section{Response of insurance industry}

The substantial increase in the number of private facilities and specialised programmes has increased the cost of psychiatric care. This has, of course, been true of all health care expenditures which have greatly outpaced inflation in general. The large, powerful insurance companies which underwrite much of the health insurance policies have responded aggressively to the increase in the cost of health care. They have instituted various regulations and procedures as to who can obtain psychiatric hospitalisation and when they can obtain it. Most of the insurers now require that prior to admission to the hospital of any patient, the insurance company should be contacted to get authorisation for admission. This so-called pre-certification involves convincing a nurse at the insurance company office that the patient needs psychiatric hospitalisation. One is expected to provide details of symptoms, diagnosis, risk of suicide, expected length of stay, and whether one explored alternate placements. The initial authorisation is typically given for a week or ten days, and periodic reports are necessary, detailing clinical symptoms and progress, for extension of stay. The request for an extension of length of stay can be denied depending on the particular situation. Then the patient's physician is left with the unpleasant dilemma of discharging the seriously ill patient or exploring other placements, as the private hospital authorities will not be prepared to keep the patient in the hospital who cannot pay for the services. 
The insurance companies have also instituted a lifetime maximum amount for psychiatric care and with the current high cost of hospital care, this amount is frequently exhausted within the first few weeks of hospitalisation, with the patient having no insurance for future psychiatric care, sometimes even for out-patient follow-up after discharge from the hospital. Both the private insurers and federal government Medicare programme also frequently rely on peer review for both quality of care and also utilisation reviews, with the bottom line being to cut costs.

\section{Advantages}

Increased privatisation has produced some advantages. Extensive marketing by private hospitals and other providers has made the general public more aware of emotional problems and they are also more willing to seek help for such problems. There has been a general reduction in stigma toward psychiatric problems and the stress model of emotional problems is something the general public seem to accept readily. There has also been pressure on politicians and law makers to mandate minimum insurance coverage, including coverage for psychiatric problems. This has helped the fight of psychiatrists and their organisations like the American Psychiatric Association to increase reimbursement for emotional problems. The insurance reimbursement for psychiatric problems has traditionally been low, with the employers offering health insurance packages with coverages for either psychiatric disorders or dental problems for instance - the so-called "mental/dental option." At present there is a bill in the US Congress (Kennedy Bill) which mandates minimum health coverage, including minimum psychiatric in-patient hospitalisation coverage and out-patient coverage. It is to be hoped that over the next several years coverage for psychiatric problems would approach coverage for other medical problems.

\section{Implications for physicians}

Physicians have generally looked at these developments with uneasiness and frustration. Doctors value autonomy very highly. The increased emphasis on cost effectiveness, productivity, efficiency, and 'bottom line' has made physicians fear loss of this autonomy. Pressures from patients' insurance companies and hospitals with conflicting demands have placed the physicians in an ethical dilemma which arises when one has to please a number of masters. As mentioned above, the insurance companies want to cut down the period of hospitalisation as hospitalisation is expensive and the private hospitals can become profitable only if the patient stays in the hospital for a long period of time. The physician has the unenviable task of balancing these conflicting demands and providing a therapeutic environment for the patient. Recent legal decisions have made it clear that the physician will be held legally liable for mishaps that happen to patients discharged prematurely because of termination of coverage by insurance companies. There have also been pressures to change patterns of practice depending on what services will be paid by the insurance companies; i.e., 'billable services.' For instance, as insurance companies do not allow weekend passes for in-patients, providers have responded by giving patients home evaluation visits over weekends. What a difference terminology makes!

Needless to say, all the above developments have affected the traditional physician/patient relationship adversely. Psychiatrists are lumped together with other health care providers, including psychologists, social workers, and therapists. In an increasingly competitive and cost conscious marketplace, a number of health care plans have realised that it is cheaper to hire non medical therapists to provide psychiatric services as physicians cost more.

\section{Conclusions and implications for the $U K$}

The trend towards privatisation of psychiatric care is growing rapidly in the USA. The factors driving this trend are complex and diverse. This system based on the consumers ability to buy a 'product' (psychiatric care) has caused a variety of problems. The physicians find themselves in the middle of conflicting pressures created by the business approach to medicine. It is ironic that after many years of emphasis on treatment of the mentally ill in the community and pressures to close psychiatric hospitals as part of the deinstitutionalisation, the pendulum has swung back to increase in the number of psychiatric beds and psychiatric hospitals. In the UK the trend toward private medical care is increasing. Although this has not affected psychiatric services in any significant way, it is possible that the pressures to privatise due to faith in market forces could increase. British doctors have traditionally enjoyed great clinical autonomy and freedom to decide what is the best form of treatment for their patients without the 'big brother' looking over their shoulders. It is important for British psychiatrists to understand that the benefits of privatisation of psychiatric care are mixed, if the American experience is anything to go by, with clinical freedom being the first casualty. 